\title{
XV. The Bakerian Lecture. An account of some new analytical researches on the nature of certain bodies, particularly the alkalies, phosphorus, sulphur, carbonaceous matter, and the acids hitherto undecomposed; with some general observations on chemical theory
}

\author{
Humphry Davy Esq. Sec. R.S. F.R.S. Edin. M.R.I.A.
}

To cite this article: Humphry Davy Esq. Sec. R.S. F.R.S. Edin. M.R.I.A. (1809) XV. The Bakerian Lecture. An account of some new analytical researches on the nature of certain bodies, particularly the alkalies, phosphorus, sulphur, carbonaceous matter, and the acids hitherto undecomposed; with some general observations on chemical theory, Philosophical Magazine Series 1, 34:136, 108-124, DOI: 10.1080/14786440908562933

To link to this article: http://dx.doi.org/10.1080/14786440908562933

Published online: 18 May 2009.

Submit your article to this journal $₫$

山 Article views: 2

Q View related articles 5 
and regularity, such as the cube, the regular octahedron, the dodecahedron with rhombous planes all equal and similar, Bec. These forms are kinds of limits which crystallization attains by different routes; while, with respect to other forms quite different from those limits, it has a single direction only which ends in any particular species of mineral.

Laws to which the Structure is suljected.-After having determined the primitive forms, and those of the integrant molecules, it remains to inquire for the laws pursued by these molecules in their arrangement, in order to produce these regular kinds of envelopes, which disguise one and the same primitive form in so many different ways.

Now observation shows that this surrounding matter is an assemblage of laminx, which, setting out from the primitive form, decrease in extent, both on all sides at once; and sometimes in certain particular parts only. This decrement is effected by regular subtractions of one or more rows of integrant molecules; and the theory, in determining the number of these rows by means of calculation, succeeds in representing all the known results of crystallization, and even anticipates future discoveries indicating forms which, being still hypothetical only, may one day be presented to the inquiries of the naturalist.

Some very simple examples will serve for giving an idea of the laws to which the. decrements in question are subjected.

[To be continued.]

$\mathrm{XV}$. The Bakerian Lecture. An Account of some new analytical Researches on the Nature of certain Bodies, particularly the Alkalies, Phosphorus, Sulphur, Carbonaceous Matter, and the Acids hitherto undecomposed; with some general Olservations on Chemical Theory. By HUMPH RY DAvY, Esq., Sec. R.S., F.R.S. Edin., and M.R.I.A.

[Continued from p. 19.]

IV. Analytical Experiments on Phosphorus.

$\mathrm{T}$ The same analogies apply to phosphorus as to sulphur, and I have made a similar series of experiments on this inflammable substance.

Common electrical sparks, passed through phosphorus, did not evolve from it any permanent gas; but when it was acted upon by the Voltaic electricity of the battery of five bundred plates in the same manner as sulphur, gas was produced in considerable quantities, and the phosphorus be- 
came of a deep red brown colour, like phosphorus that has been inflamed and extinguished under water. The gas examined proved to be phosphuretted hydrogen, and in one experiment, continued for some hours, a quantity estimated to be nearly equal to four times the volume of the phosphorus employed was given off. The light of the Voltaic spark in the phosphorus was at first a brilliant yellow, but as the colour of the phosphorus changed, it appeared orange.

I heated three grains of potassium in sixteen cubical inches of phosphuretted hydrogen; as soon as it was fused, the retort became filled with white fumes, and a reddish substance precipitated upon the sides and upper part of it. The heat was applied for some minutes. No inflammation took place*. When the retort was cool, the absorption was found to be less than a cubical inch. The potassium externally was of a deep brown colour, internally it was of a dull lead colour. The residual gas had lost its property of spontaneous inflammation, but seemed still to contain a small quantity of phosphorus in solution.

The phosphuret acted upon over mercury by solution of muriatic acid evolved only one cubical inch and three quarters of phosphuretted hydrogen.

From this experiment, there is great reason to suppose that phosphuretted hydrogen contains a minute proportion of oxygen, and consequently that phosphorus likewise may contain it; but the action of potassium on phosphorus itself furnishes perhaps more direct evidences of the circumstance.

One grain of potassium and one grain of phosphorus were fused together in a proper apparatus. They combined with the production of the most vivid light and intense ignition. During the process one-tenth of a cubical inch of phosphuretted hydrogen was evolved. The phosphuret formed, exposed to the action of diluted muriatic acid over mercury, produced exactly three-tenths of a cubical inch of phosphuretted hydrogen.

In a second experiment, one grain of potassium was fused with three grains of phosphorus; in this case nearly a quarter of a cubical inch of phosphuretted hydrogen was generated during the ignition. But from the compound exposed to muriatic acid, only one-tenth of a cubical inch could be procured.

Now it is not easy to refer the deficiency of phosphuretted

- It is stated, in the account before referred to of MM. Gay Lussac's and Thenard's experiments, that potassium inflames in phosphuretted hydrogen. My experiments upon this gas have been often repeated. 1 have never.perceived any luminous appearance; but I have always operated in daylight. 
hydrogen in the eecond case to any other cause than to the supply of oxygen to the potassium from the phosphorus and the quantity of phosphuretted hydrogen evolved in the first case, is much less than could be expected, if both potassium and phosphorus consisted merely of pure combustible matter.

The phosphoric acid, formed by the combustion of phosphorus, though a crystalline solid, may still contain water. The hydrogen evolved from phosphorus by electricity proves indeed that this must be the case; and though the quantity of hydrogen and oxygen in phosphorus may be exceedingly small, yet they may be sufficient to give it peculiar characters; and till the basis is obtained free, we shall have no knowledge of the properties of the pure phosphoric element.

\section{On the States of the carbonaceous Principle in Plumbago, Charcoal, and the Diamond.}

The accurate researches of Messrs. Allen and Pepys have distinctly proved, that plumbago, charcoal, and the diamond, produce very nearly the same quantities of carbonic acid, and absorb very nearly the same quantities of oxygen in combustion.

Hence it is evident, that they must consist principally of the same kind of elementary matter; but minute researches upon their chemical relations, when examined by new analytical methods, will, I am inclined to believe, show that the great difference in their physical properties does not merely depend upon the differences of the mechanical arrangement of their parts, but likewise upon differences in their intimate chemical nature.

I endeavoured to discover, whether any elastic matter could be obtained from plumbago very intensely ignited by the Voltaic battery in a Torricellian vacuum: but though the highest power of the battery of five hundred was employed, and though the heat was such, as in another experiment instantly melted platina wire of $\sigma^{\frac{2}{6}} 0^{\mathrm{t}} \mathrm{h}$ of an inch in diameter, yet no appearance of change took place upon the plumbago. Its characters remained wholly unaltered, and no permanent elastic fluid was formed.

I heated one grain of plumbago, with twice its weight of potassium, in a plate glass tube connected with a proper apparatus, and I heated an equal quantity of potassium alone in a tube of the same kind, for an equal length of time, namely, eight minutes. Both tubes were filled with hydrogen : no gas was evolved in either case. There was no igui- 
tion in the tube containing the plumbago, but it seemed gradually to combine with the potassium. The two results were exposed to the action of water; the result from the plumbago acted upon that fluid with as much energy as the other result, and the two volumes of elastic fuids were 1.8 cubical inches and 1.9 cubical inches; and both gave the same diminution by detonation with oxygen, as pure hydrogen. Two grains of potassium, by acting upon water, would have produced two cubical inches and oneeighth of hydrogen gas; the deficiency in the result, in which potassium alone was used, must be ascribed to the loss of a small quantity of metal, which must have been carried off in solution in the hydrogen, and perhaps, likewise, to the action of the minute quantity of metallic oxides in the plate glass. The difference in the quantity of hydrogen given off in the two results, is however too slight to ascribe it to the existence of oxygen in the plumbago.

1 repeated this experiment several times with like results, and in two or three instances examined the compound formed. It was infusible at a red heat, had the lustre of plumbago. It inflamed spontaneously, when exposed to air, generated potash, and left a.black powdery residuum. It effervesced most violently in water, and produced a gas, which burnt like pure hydrogen.

When small pieces of charcoal from the willow, that had been intensely ignited, were acted upon by Voltaic electricity in a Torricellian vacuum, every precaution being taken to exclude moisture from the mercury and the charcoal, the results were very different from those occurring in the case of plumbago.

When plumbago was used, after the first spark, which generally passed through a distance of about one-eighth of an inch, there was no continuation of light, without a contact or an approach to the same distance; but from the charcoal a flame seemed to issue of a most brilliant purple, and formed, as it were, a conducting chain of light of nearly an inch in length, at the same time that elastic matter was rapidly formed, some of which was permanent. After many unsuccessful trials, I at length succeeded in collecting the quantity of elastic fluid given out by half a grain of charcoal; the process had been continued nearly half an hour. The quantity of gas amounted to nearly an eighth of a cubical inch; it was inflammable by the electric spark with oxygen gas, and four measures of it absorbed three measures of oxygen, and produced one measure and a half of carbonic acid. The charcoal in this experiment had 
become harder at the point, and its lustre, where it had been heated to whiteness, approached to that of plumbago.

I heated two grains of potassium together with two grains of charcoal, for five minutes; and to estimate the effects of the metalfic oxides and potash in the green glass lube, I made a comparative experiment, as in the case of plumbago; but there was no proof of any oxygen being furnished to the potassium from the charcoal in the process, for the compound acted upon water with great energy, and produced $a$ quantity of inflammable gas, only inferior by one-twelfth to that produced by the potassium, which had not been combined with charcoal, and which gave the same diminution by detonation with oxygen; and the slight difference may be well ascribed to the influence of foreign matters in the charcoal. There was no ignition in the process, and no gas was evolved.

The compound produced in other experiments of this kind was examined. It is a conductor of electricity, is of a dense black; inflames spontameously, and burns with a deep red light in the atmosphere*.

The non-conducting nature of the diamond, and its infusibility, rendered it impossible to act upon it by Voltaic eleeiricity; and the only new agents which seemed to offer any ineans of decomposing it, were the metals of the alkalies.

When a diamond is heated in a green glass tube with potassium, there is no elastic fluid given out, and no intensity of action; but the diamond soon blackens, and scales seem to detach themselves from it; and these scales, when exanined in the maynifier, are gray externally, and of the colour of plumbago internally, as if they consisted of plumbago covered by the gray oxide of potassium.

Fin heating together three grains of diamonds in powder, and two grains of potassium, for an hour in a small retort of plate glass filled with hydrogen, and making the comparative trial with two grains of potassium heated in $\mathbf{x}$ simifar apparatus, without any diamonds, I found that the potassitum which had been heated with the diamonds, produced, by its action upon water, one cubical inch and $\frac{5}{10}$ ths of intammable air, and that which had been exposed to heat sone; all other circumstances being similar, evolved nearly one cubical inch and riths, both of which were pure hy* drogen.

- In the Bakerian Lectute for 1807, I have mentioned the decompesition af carbonic acid by potassium, which takes place with inflammation. If the potassium is in excess in this experimeat, the same pyrophorus as that de. ecribed above is formed. 
In another experiment of a similar kind, in which fragments of diamonds were used in the quantity of four grains, the putassium became extremely black from its action upon them during an exposure to heat for three hours, and the diamonds were covered with a grayish crust, and when acted upon by water and dried, were found to have lost about $\frac{28}{100}$ ths of a grain in weight. The matter separated by washing, and examined, appeared as a fine powder of a dense black colour. When a surface of platina wire was covered with it, and made to touch another wire in the Voltaic circuit, a brilliant spark with combustion occurred. It burnt, when heated to redness in a green glass tube filled with oxygen gas, and produced carbonic acid by its combustion.

These general resulis seem to show, that in plumbago the carbonaceous element exists mcrely in combination with iron, and in a form which may be regarded as approsching to that of a metal in its nature, being conducting in a high degree, opaque, and possessing considerable lustre.

Charcoal appears to contain a minute quantity of hydrogen in combination. Possibly likewise, the alkalies and earths produced during its combustion, exist in it not fully combined with oxygen; and according to these ideas, it is a very compounded substance, though in the main it consists of the pure carbonaceous element.

The experiments on the diamond render it extremely likely that it contains oxygen; but the quantity must be exceedingly minute, though probably sufficient to render the compound non-conducting: and if the carbonaceous element in charcoal and the diamond be considered as united to still less foreign matter in quantity, than in plumbago, which contains about $\frac{1}{2}$ th of iron, the results of their combustion, as examined independently of hygrometrical tests, will not differ perceptibly:

Whoever considers the difference between iron and steel, in which there does not exist more than or the difference between the amalgam of ammonium, and mercury, in which the quantity of new matter is not more than $\frac{1}{1200}$ th, or that between the metals and their suboxides, some of which contain less than $\frac{1}{i n}$ th of oxygen, will not be disposed to question the principle, that minute differences in chemical composirion may produce great differences in external and physical characters.

\section{Experiments on the Decomposition and Composition of the Boracic Acid.}

In the last Bakerian Lecture, I have given an account of Vol, 34. No. 136. August 1809 . 
an experiment in which boracic acid appeared to be decomposed by Voltaic electricity, a dark-coloured intlammable substance separating from it on the negative surface.

In the course of the spring and summer, I made many attempts to collect quantities of this substance for minute examination. When boracic acid, moistened with water, was exposed between two surfaces of platina, acted on by the full power of the battery of five hundred, an olive-brown matter immediately began to form on the negative surface, which gradually increased in thickness, and at last appeared almost black. It was permanent in water, but soluble with effervescence in warm nitrous acid. When heated to redness upon the platiua it burnt slowly, and gave off white fumes, which slightly reddened moistened litmus paper, and it left a black mass, which, when examined by the magnifier, appeared vitreous at the surface, and evidently contained a fixed acid.

These circumstances seemed distinctly to show the decomposition and recomposition of the boracic acid; but as the peculiar combustible substance was a non-conductor of electricity, I was never able to obtain it, except in very thin films upon the platina. It was not possible to examine its properties minutely, or to determine its precise nature, or whether it was the pure boracic basis; I consequently endeavoured to apply other methods of decomposition, and to find other more unequivocal evidences upon this important chemical subject.

I have already laid before the Society an account of an experiment *, in which boracic acid, heated in contact with potassinm in a gold tube, was converted into borate of potash, at the same time that a dark-coloured matter, similar to that produced from the acid by electricity, was formed. About two months after this experiment had been made, namely, in the beginning of Augrust, at a time that I was repeating the process, and examining minutely the results, I was informed, by a letter from Mr. Cadell at Paris, that M. Thenard was employed in the decomposition of the boracic acid by potassium, and that he had heated the two substances together in a copper tube, and had obtained borate of potash, and a peculiar matter concerning the nature of which no details were given in the communication.

That the same results must be obtained by the same methods of operating, there could be no doubt. The evidences for the decomposition of the horacic acid are easily gained,

* Philcsophical Transactions, Part II. for 1808, p. 349. 
the synthetical proofs of 1 ts nature involve more complicated circumstances.

1 found that when equal weights of potassium and boracic acid were heated togetber in a green glass tube, which had been exhausted after having been twice filled with hydrogen, there was a most intense ignition before the temperature was nearly raised to the red heat; the potassium entered into vivid inflammation, where it was in contact with the boracic acid. When this acid had been heated to whiteness, before it was introduced into the tube, and powdered and made use of whilst yet warm, the quantity of gas given out in the operation did not exceed iwice the volume of the acid, and was hydrogen.

I could only use twelve or fourteen grains of each of the two substances in this mode of conducting the experiment; for when larger quantities were employed, the glass tube always ran into fusion from the intensity of the heat produced during the action.

When the film of naphtha bad not been carefully removed from the potassium, the mass appeared black throughout; but when this had been the case, the colour was of a dark olive-brown.

In several experiments, in which' I used equal parts of the acid and metal, I found that there was always a great quantity of the former in the residuum; and by various trials, $I$ ascertained that $t$ wenty grains of potassium had their inflammability entirely destroyed by about eight grains of boracic acid.

For collecting considerable portions of the matters formed in the process, I used metallic tubes furnished with stopcocks, and exhausted after being filled with hydrogen.

When tubes of brass or copper were employed, the heat was only raised to a dull red; but when iron tubes were used, it was pushed to whiteness. In all cases the acid was decomposed, and the products were scarcely different.

When the result was taken out of a tube of brass or copper, it appeared as an olive-coloured glass, having opaque, dull olive-brown specks diffused through it.

It gave a very slight effervescence with water, and partially dissolved in hot water, a dark olive-coloured powder separating from it.

The results from the iron tube, which had been much more strongly heated, were dark olive in some parts, and almost black in others. They did not effervesce with warm water, but were rapidly acted upon by it, and the particles $\mathrm{H} 2$ separated 
separated by washing were of a shade of olive, so dark as to appear almost black on white paper.

The solutions obtained, when passed through a filter, had a faint olive tint, and contained sub-borate of potash, and potash. In cases when, instead of water, a weak solution of muriatic acid was used for separating the saline matter from the inflammable matter, the fluid came through the filter colourless.

In describing the properties of the new inflammable substance separated by washing, I shall speak of that collected from operations conducted in tubes of brass, in the manner that has been just mentioned; for it is in this way that I have collected the largest quantities.

It appears as a pulverulent mass of the darkest shades of olive. It is perfectly opaque. It is very friable, and its powder does not scratch glass. It is a non-conductor of electricity.

When it has been dried only at 100 or $120^{\circ}$, it gives off moisture by increase of temperature, and if heated in the atmosphere, takes fire at a temperature below the boiling point of olive oil, and burns with a red light and scintillations like charcoal.

If it be excluded from air and heated to whiteness in a tube of platina, exhausted after having been filled with hydrogen, it is found very little altered after the process. Its colour is a little darker, and it is rather denser; but no indications are given of any part of it having undergone fusion, volatilization, or decomposition. Before the process its specific gravity is such that it does not sink in sulphuric acid; but after, it rapidly falls to the bottom in this fluid.

The phanomena of $\mathrm{jts}$ conbustion are best witnessed in a retort filled with oxygen gas. When the bottom of the retort is gently heated by a spirit lamp, it throws off most vivid scintillations like those from the combustion of the bark of charcoal, and the mass burns with a brilliant light. A sublimate rises from it, which is boracic acid; and it becomes coated with a vitreous substance, which proves likewise to be boracic acid; and after this has been washed off, the residuum appears perfectly black, and requires a higher temperature for its inflammation than the olive-coloured substance; and by its inflammation produces a fresh portion of boracic acid.

In oxymuriatic acid gas, the peculiar inflammable substance occasions some beautiful phænomena. When this gas is brought in contact with it at common temperatures, 
it instantly takes fire and burns with a brilliant white light, a white substance coats the interior of the vessel in which the experiment is made, and the peculiar substance is found covered by a white film, which, by washing, affords boracic acid, and leaves a black matter, which is not spontaneously inflammable in a fresh portion of the gas; but which inflames in it by a gentle heat, and produces boracic acid.

The peculiar inflammable substance, when heated nearly to redness in hydrogen, or nitrogen, did not seem to dissolve in these gases, or to act upon them; it merely gained a darker shade of colour, and a little moisture rose from it, which condensed in the neck of the retort in which the experiment was made.

On the fluid menstrua containing oxygen, it produced effects which might be looked for from the phænomena of its agency on gases.

When thrown into concentrated nitric acid, it rendered it bright red, so that nitrous gas was produced and absorbed, but it did not dissolve rapidly till the acid was heated; when there was a considerable effervescence, the peculiar substance disappeared, nitrous gas was evolved, and the fluid afforded boracic acid.

It did not act upon concentrated sulphuric acid till heat was applied; it then produced a slight effervescence; the acid became black at its points of contact with the solid; and a deep brown solution was formed, which, when neutralized by potash, gave a black precipitate.

When heated in a strong solution of muriatic acid, it gave it a faint tint of green; but there was no vividness of action, or considerable solution.

On acetic acid heated, it had no perceptible action.

It combined with the fixed alkalies, both by fusion and aqueous solution, and formed pale olive-coloured compounds, which gave dark precipitates when decomposed by muriatic acid.

When it was kept long in contact with sulphur in fusion, it slowly dissolved, and the sulphur acquired an olive tint. It was still less acted upon by phosphorus, and after an hour's exposure to it, had scarcely diminished in quantity, but the phosphorus had gained a tint of pale green.

It did not combine with mercury, when they were heated together.

These circumstances are sufficient to show, that the combustible substance obtained from horacic acid by the agency of potassium, is different from any other known species of matter, and it seems, as far as the evidence extends, to be H 3 the 
the same as that procured from it by electricity; and the two series of facts seem fully to establish the decomposition and recomposition of the acid.

From the large quantity of potassium required to decompose a small quantity of the acid, it is evident that the boracic acid must contain a coniderable proportion of oxygen. I have endeavoured to determine the relative weights of the peculiar inflammable matter and oxygen, which compose a given weight of boracic acid; and to this end I made several analytical and synthetical experiments; I shall give the results of the two which $I$ consider most accurate.

Twenty grains of boracic acid and thirty grains of potassium were made to act upon each other by heat in a tube of brass.; the result did not effervesce when washed with dilitted muriatic acid; and there were obtained after the process, by slight lixiviation in warm water, two grains and about $\frac{s}{6}$ ths of the olive-coloured matter. Now thirty grains of potassium would require about five grains of oxvgen, to form thirty-five of potash ; and according to this estimation, boracic acid must consist of about one of the peculiar inflammable substance, to nearly two of oxvgen.

A grain of the inflammable substance in very fine powder, and diffused over a large surface, was set fire to in a retort, containing twelve cubical inches of oxygen; three cubical inches of gas were absorbed, and the black residuum collected after the boracic acid had been dissolved, was found to equal five-eighths of a grain. This, by a second combus. tion, was almost entirely converted into boracic acid, with the absorption of two cubical inches and one-eighth more of oxygen. The thermometer in this experiment was at $58^{\circ}$ Fahrenheit, and the barometer at 30:2.

According to this result, boracic acid would consist of one of the inflammable matter, to about 1.8 of oxygen; and the dark residual substance, supposing it to be simply the inflammable matter cumbined with less oxygen than is sufficient to constilute boracic acid, would be an axide, consisting of about 47 of inflammable matter, to 1.55 of oxygen.

These estimations I do not however venture to give as entirely correct. In the analytical experiments, there are promably sources of error, from the solution of a part of the inflammable matter, and it possibly may retain alkali, which cannot be separated by the acid. In the synthetical process, in which washing is employed, and so small a quantity of matter used, the results are still less to be depended upon; they must be considered only as imperfect approximamons. 
From the general tenour of the facts, it appears that the combustible matter obtained from boracic acid bears the same relation to that substance, as sulphur and phosphorus do to the sulphuric and phosphoric acids. But is it an elementary inflammable body, the pure basis of the acid? or is it not like sulphur and phosphorus, compounded?

Without entering into any discussion concerning ultimate elementary matter, there are many circumstances which favour the idea, that the dark olive substance is not a simple body; its being non-conducting, its change of colour by being heated in hydrogen gas, and its power of combining with the alkalies ; for these properties in general belong to primary compounds, that are known to contain oxygen.

I heated the olive-coloured substance with potassium, there was a combination, but without any luminous appearance, and a gray metallic mass was formed; but from the effect of this upon water, I could not affirm that any oxygen had been added to the metal, the gas given off had a peculiar smell, and took up more oxygen by detonation than pure hydrogen, from which it seems probable, that it held some of the combustible matter in solution.

It occurred to me, that if the pure inflammable basis were capable of being deoxygenated by potassium, it' would probably possess a stronger affinity for oxygen than hydrogen, and therefore be again brought to its former state by water. I made another expcriment on the operation of pctassium, on the olive-coloured substance, and exposed the mixture to a small quantity of ether, hoping that this might contain only water enough to oxygenate the potassium; but the same result occurred as in the last case; and a combination of potash and the olive-coloured substance was produced, insoluble in ether.

I covered a small globule of potassium, with four or five times its weight of the olive-coloured matter, in a platina tube exhausted, after being filled with hydrogen; and heated the mixture to whiteness : no gas was evolved. When the tube was cooled, naphtha was poured into it, and the result examined under naphtha. Its colour was of a dense black. It had a lustre scarcely inferior to that of plumbago. It was a conductor of electricity. A portion of it thrown into water occasioned a slight effervescence; and the solid matter separated appeared dark olive, and the water became slightly alkaline. Another portion examined, after being exposed to air for a few minutes, had lost its conducting power, was brown on the surface, and no longer produced an effervessence in water. 
Some of the olive inflammable matter, with a little potas. sium, was heated to whiteness, covered with iron filings, a dark metalline mass was formed, which conducted electricity, and which produced a very slight effervescence in water, and gave by solution in nitric acid, oxide of iron and boracic acid.

The substance which enters into alloy with potassium, and with iron, I am inclined to consider as the true basis of the boracic acid.

In the olive-coloured matter, this basis seems to exist in union with a little oxygen; and when the olive-coloured substance is dried at common temperatures, it likewise contains water.

In the black non-conducting matter, produced in the combustion of the olive-colsured substance, the basis is evidently combined with much more oxygen, and in its full state of oxygenation it constitutes boracic acid.

From the colour of the oxides, their solubility in alkalies, and from their general powers of combination, and from the eonducting nature and lustre of the matter produced by the action of a small quantity of potassium upon the olive-coloured substance, and from all analogy ; there is strong reason to consider the boracic basis as metallic in its nature, and I venture to propose for it the name of boracium.

\section{Analytical Inquiries respecting Fluoric Acid.}

I have already laid before the Society the account of my first experiments on the action of potassium on fluoric acid gas*.

I stated, that the metal burns when heated in this elastic fluid, and that there is a great absorption of the gas.

Since the time that this communication was made, I have carried on various processes, with the view of ascertaining, accurately, the products of combustion, and I shall pow describe their results.

When fluoris acid gas, that has been procured in contact with glass, is introduced into a plate glass retort, exhausted after being filled with bydrogen gas, white fumes are immediaicly perceived. The metal loses its splendour, and becomes covered with a gravish crust.

When the bottom of the returt is gently heated, the fumes

* Philosophical Transactions, Part II., for 1808, p 343. The combustion of notassium in fuoric acid I have since seen mentioned in the number of the Moniteur aiready sr, often quoted, as observed by MM. Gay Lussac and Thenard; but no notice is taken of the results. 
become more copious; they continue for some time to be emitted, but at last cease altogether.

If the gas is exanined at this time, its volume is found to be a little increased, by the addition of a small quantity of hydrogen.

No new fumes are produced by a second application of a low heat; hut when the temperature is raised nearly to the point of sublimation of potassium, the metal rises through the crust, becomes first of a copper eolour and then of a blueish black, and soon after inflames and burns with a most brilliant red light.

After this combustion, either the whole or a part of the fluoric acid, according as the quantity of potassium is great or small, is found to be destroyed or abs urbed. A mass of a chocolate colour remains in the bottom of the retort; and a sublimate, in some parts chocolate, and in others yellow, is found round the siles, and at the top of the retort.

When the residual gas afforded by this operaiion is washed with water, and exposed to the action of an electrical spark mixed with oxygen gas, it detonater, and affords a diminution such as might be expected trom hydrogen gas.

The proportional quantity of this elastic flund differs a little in different operations. When the Hunric acid has not been artificially dried, it amounts to one sixth or one-seventh of the volume of the acid gas used; but when the fluoric acid has been long exposed to calcined sulphate of soda, it seldom amounts to one-tenth.

I have endeacoured to collect large quantities of the chocolate-coloured substance for minute examination ; but some difficulties occurred.

When I used from eighteen to twenty grains of potassium, in a retort containing from twenty to thirty cubical inches of fluoric acid gas, the intensity of the heat was such, as to fuse the bottom of the retort, and destroy the results.

In a very thick plate glass retort, containing about nineteen cubical inches of gas, I once succeeded in making a decisive experiment on ten grains and a half of potassium, and I found that about fourteen cubical inches of fluoric acid disappeared, and about two and a quarter of hydrogen gas were evolved. The barometer stood at $30 \cdot 3$, and the thermometer at $61^{\circ}$ Fahrenheit; the gas had not been artificially dried. In this experiment there was very little sublimate; but the whole of the bottom of the retort was covered with a brown crust, and near the point of contact with the bottom the substance was darker coloured, and approaching in its tint to black. 
When the product was examined by a magnifier, it evidently appeared consisting of different kinds of matter; a blackish substance, a white, apparently saline substance, and a substance having different shades of brown and fawn colour.

The mass did not conduct electricity, and none of its parts could be separated, so as to be examined as to this property.

When a portion of it was thrown into water, it effervesced violently, and the gas evolved had some resemblance in smell to phosphuretted hydrogen, and was inflammable.

When a part of the mass was heated in contact with air, it burnt slowly, lost its brown colour, and became a white saline mass.

When heated in oxygen gas, in a retort of plate glass, it absorbed a portion of oxygen, but burnt with difficulty, and required to be heated nearly to redness; and the light given out was similar to that produced by the combustion of liver of sulphur.

The water which had acted upon a portion of it was examined; a number of chocolate-coloured particles floated in it. When the solid matter was separated by the filter, the fluid was found to contain fluate of potash, and potash. The solid residuum was heated in a small glass retort in oxygen gas ; it burnt before it had attained a red heat, and became white. In this process, oxygen was absorbed, and acid matter produced. The remainder possessed the properties of the substance formed from fluoric acid gas holding siliceous earth in solution, by the action of water.

In experiments made upon the combustion of quantities of potassium equal to from six to eleven grains, the portion of matter separable from the water has amounted to a very small part of a grain onlý, and operating upon so minute a scale, I have not been able to gain fully decided evidence, that the, inflammable part of it is the pure basis of the fluoric acid ; but with respect to the decomposition of this budy by potassium, and the existence of its basis at least combined with a smaller proportion of oxygen in the solid product generated, and the regeneration of the acid by the ignition of this product in oxygen gas, it is scarcely possible to entertain a doubt.

The decomposition of the fluoric acid by potassium, seems analogous to that of the acids of sulphur and phosphorus. In neither of these cases are the pure bases, or even the bases in their common form evolved; but new compounds result, and in one case sulphurets, and sulphites, and 
in the other phosphurets, and phosphites of potash, are generated.

As silex was always obtained during the combustion of the chocolate-coloured substance obtained by lixiviation, it occurred to me that this matter might be a result of the operation, and that the chocolate substance might be a compound of the siliceous and fluoric bases in a low state of oxygenation, with potash; and this idea is favoured by some trials that I made to separate silex from the mass, by boiling it in concentrated fluoric acid; the substance did not seem to be much altered by this process, and still gave silex by combustion,

I endeavoured to decompose fluoric acid gas in a perfectly dry state, and which contained no siliceous earth; and for this purpose I made a mixture of one hundrea grains of dry boracic acid, and two hundred grains of fluor spar, and placed them in the bottom of an iron tube, having a stopcock and a tube of safety attached to it.

The tube was inserted horizontally in a forge, and twenty grains of potassium, in a proper iron tray, introduced into that part of it where the heat was only suffered to rise to dull redness. The bottom of the tube was heated to whiteness, and the acid acted upon by the heated potassium, as it was generated. Atter the process was finished, the result in the tray was examined.

It was in some parts black, and in others of a dark brown. It did not effervesce with water; and, when lixiviated, afforded a dark brown combustible mass, which did not conduct electricity, and which, when burnt in oxygen gas, afforded boracic and funric acid. It dissolved with violent effervescence in nitric acid; but did not inflame spontaneously in oxymuriatic acid gas.

I have not as yet examined any of the other properties of this substance; but $!$ am inclined to consider it as a compound of the olive-coloured oxide of boracium, and an oxide of the fluoric basis.

In examining the dry fluoric acid gas, procured in a process similar to that which has been just described, it gave very evident marks of the presence of boracic acid.

As the chocolate-coloured substance is permanent in water, it occurred to me that it might possibly be producible from concentrated liquid fluoric acid at the negative surface in the Voltaic circuit.

I made the experiment with platina surfaces, from a battery of two hundred arsd fifty plates of six inches, on fluoric acid the densest that could be obtained by the distillation of 
fluor spar and concentrated sulphuric acid of commerce, in vessels of lead. Oxygen and hydrogen were evolved, and a dark brown matter separated at the deoxidating surface ; but the result of an operation conducted for many hours, merely enabled me to ascertain that it was combustible, and produced acid matter in combustion; but I cannot venture to draw the conclusion that this acid was fluoric acid, as it was not impossible that some sulphureous, or sulphuric acid might likewise exist in the solution.

I heated the olive-coloured inflammable substance, obtained from the boracic acid, in common fluoric acid gas in a plate glass retort ; the temperature was raised till the glass began to fuse; but no change, indicating a decomposition, took place.

I heated six grains of potassium with four grains of powdered fluor spar in a green glass tube filled with hydrogen; there was a slight ignition, a minute quantity of hydrogen gas was evolved, and a dark gray mass was produced, which acted upon water with much effervescence, but left no solid inflammable residuum.

[To be continued.]

XVI. Suggestion for establishing a Telegraphic Intercourse letween London and Dullin. By the Rev. Mr. JaMes HaLl.

To Mr. Tilloch,

SIR, $A_{s}$ it is the duty of every good subject to contribute what he can to the service of his country, I have ventured to trouble you with the following hints on the subject of telegraphs.

Previous to my setting out for-Ireland, (through the greater part of which I travelled lately,) I began to study the physical geography of that country. On turning my attention to this matter, and conversing with Dr. Thomson of Kensington Gravel Pits, and others, on the subject, the Doctor drew my atiention to the circumstance, that the old maps of Ireland, particularly those of the fifteenth century, and about the time of the Spanish armada, laid down the northern parts of that kingdom much nearer the Mull of Cantire, in Scotland, than the modern maps in general do. The question then was, Whether the maps of Ireland of the fifteenth, or those of the present century, are the more correct? On arriving at Torr Point, Fair Head, the nearest point of Ireland to Scotland, I hired a boat and sailed to Cantire. 